\title{
Script Characterization in the Old Slavic Documents
}

\author{
Darko Brodić ${ }^{1}$, Zoran N. Milivojević ${ }^{2}$, and Čedomir A. Maluckov ${ }^{1}$ \\ 1 University of Belgrade, Technical Faculty in Bor, \\ Vojske Jugoslavije 12, 19210 Bor, Serbia \\ 2 College of Applied Technical Sciences Niš, \\ Aleksandra Medvedeva 20, 18000 Niš, Serbia \\ dbrodic@tf.bor.ac.rs
}

\begin{abstract}
The paper addressed the problem of the script characterization in the old Slavic printed documents. Therefore, an algorithm for the script discrimination was proposed. It was based on the typographical feature classification, which creates ciphers from different scripts of the document. Then, the feature extraction was achieved by statistical analysis. The obtained features were set and stored for further analysis in order to identify the discrimination criteria between different scripts. The proposed method is tested on the example of the Slavic printed documents which contains Glagolitic and Cyrillic script.
\end{abstract}

Keywords: Cryptography, Script recognition, Optical character recognition, Statistical analysis, Typographical features.

\section{Introduction}

Optical character recognition (OCR) is a computer based system that recognizes the scanned printed, hand printed or handwritten documents. It consists of a few stages such as: preprocessing, feature extraction, classification and postprocessing [1]. One of the main parts that represents the feature extraction stage is a script recognition module.

In this paper, we introduced an algorithm for the script recognition based on typographical features, cryptography and statistical analysis. This method established discrimination criteria for the identidication of different scripts in the old Slavic printed documents. In its first part, the algorithm classified all letters according to theirs typographical features. Then, the data were encrypted creating cipher [2. The encryption was made by a cryptographic algorithm [3] that belongs to hash function (HF) 4]. It irreversibly encrypted the initial information. Nevertheless, the cryptography was used as a base for modeling only [5]. Hence, decryption was not required. This way, the model was established by replacing each letter in the text with the cipher using a similar approach as in [5]. After that, the gray-level co-occurrence matrix (GLCM) was calculated to extract the certain texture features [6]. The analysis of these features were 
made along with their classification. At the end, the criteria for discrimination between scripts was established.

The rest of the paper is formed as follows: Section 2 addresses all aspects of the proposed algorithm. It includes script mapping, encryption, co-occurrence analysis, and features extraction. Section 3 defines the custom oriented script database for the experimentation. Section 4 discusses the results of the experiment. Section 5 makes conclusions.

\section{Proposed Algorithm}

The proposed algorithm consists of the stages that follows: (i) script mapping, (ii) encryption, (iii) co-occurrence analysis, and (iv) features extraction.

\subsection{Script Mapping}

All letters in certain script have different typographical features according to their position in the text line [7]. Hence, the structure of the text line can be divided into: (i) upper zone, (ii) middle zone, and (iii) lower zone [8]. Short letters (S) like a small letter a are located in the middle zone. Ascender letters (A) like capital letter $\mathbf{k}$ outlay the middle and upper zones. Descender letter (D) like small letter $\mathbf{p}$ outspread over the middle and lower zone. Full letters (F) like the capital letter $\mathbf{j}$ occupy all three zones. Fig. 1] illustrates the script type definition.

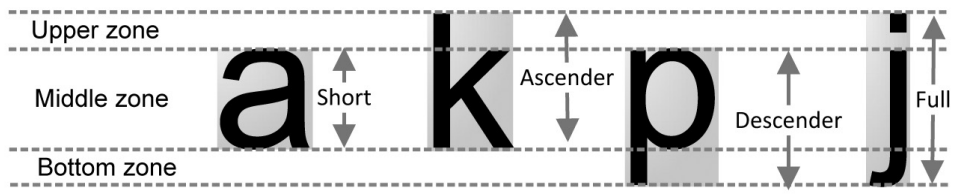

(a)

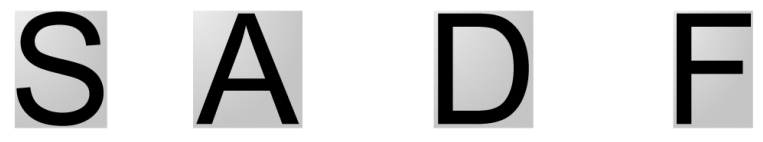

(b)

Fig. 1. Script type $(S T)$ illustration: (a) Letter samples, and (b) Equivalent script types

Consequently, all letters from different scripts in the old Slavic documents are mapped into the script type set $S T$ :

$$
S T=\{\mathrm{S}, \mathrm{A}, \mathrm{D}, \mathrm{F}\} .
$$




\subsection{Encryption}

The data needs to receive a form that is suitable for the statistical analysis. Hence, the set $S T$ is encrypted into the cipher set $C$.

$$
C=\{0,1,2,3\},
$$

where $\mathrm{S} \longrightarrow 0, \mathrm{~A} \longrightarrow 1, \mathrm{D} \longrightarrow 2$, and $\mathrm{F} \longrightarrow 3$. Fig 2 illustrates Cyrillic and Glagolitic alphabet according with their cipher counterparts.

а б в

$\begin{array}{lllllllllllllllllllllllllllllll}0 & 1 & 0 & 0 & 2 & 3 & 0 & 0 & 0 & 0 & 3 & 0 & 0 & 0 & 0 & 0 & 0 & 0 & 0 & 2 & 0 & 0 & 1 & 2 & 3 & 0 & 2 & 0 & 2 & 0\end{array}$

А Б В Г Д Ђ

$\begin{array}{llllllllllllllllllllllllllllll}1 & 1 & 1 & 1 & 2 & 1 & 1 & 1 & 1 & 1 & 1 & 1 & 1 & 1 & 1 & 1 & 1 & 1 & 1 & 1 & 1 & 1 & 1 & 1 & 1 & 1 & 3 & 1 & 3 & 1\end{array}$

(a)

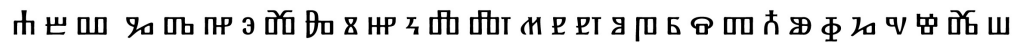

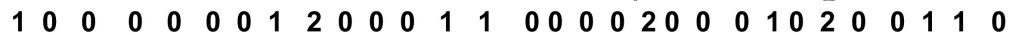

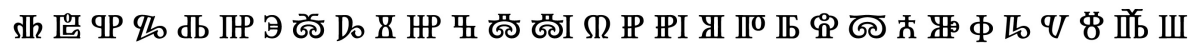

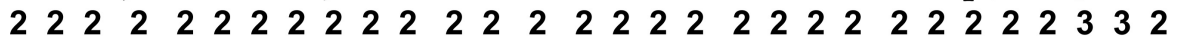

(b)

Fig. 2. Encryption: (a) Cyrillic alphabet and cipher counterparts, (b) Glagolitic alphabet and cipher counterparts

\subsection{Statistical Analysis}

The proposed algorithm exchanges all letters from a certain script with the equivalent members of the set $C$ (See Fig. 2 for reference). The obtained cipher is subjected to a co-occurrence analysis [6]. This way, the texture features is calculated according to co-occurrence probabilities. These probabilities represent the conditional joint probabilities of all pair wise combinations of gray levels in the spatial window of interest (WOI). Three parameters can be considered in order to describe the image with GLCM: (i) the number of gray levels $(G)$, (ii) the orientation angle $(\theta)$ and (iii) the length of displacement, i.e. the inter-pixel distance of the window of interest $(d)[9]$. Fig. 3 illustrates the window size for calculating the Haralick texture features.

The method starts up in the top left corner and counts the occurrences of each reference pixel to neighbor pixel relationship. This way, each element $(i, j)$ of GLCM is the sum of the number of times the pixel with the value $i$ was located at some distance $d$ and angle $\theta$ from the pixel of intensity $j$. At the end 


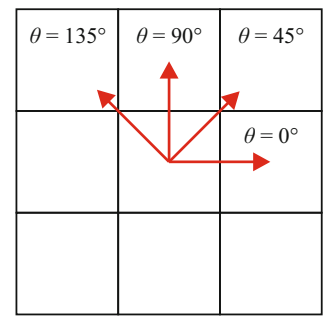

Fig. 3. Illustration of the WOI (the four directions of adjacency for calculating the Haralick texture features with $d=1$ )

of this process, the element $(i, j)$ gives the number that represents how many times the gray levels $i$ and $j$ appears as a sequence of two pixels located at a defined distance $d$ along a chosen direction $\theta$. Mathematically, the GLCM for an image $I(x, y)$ featuring $M$ rows and $N$ columns is parameterized by the offset $(\Delta x, \Delta y)$ as:

$$
P(i, j)=\sum_{x=1}^{M} \sum_{y=1}^{N}\left\{\begin{array}{lc}
1 \text { if } & I(x, y)=i, \\
0 & \text { otherwise }
\end{array} \quad I(x+\Delta x, y+\Delta y)=j\right.
$$

The offset $(\Delta x, \Delta y)$ characterizes the pixel displacement $d$ and the orientation $\theta$ at which the co-occurrence matrix is calculated. In our example, the text characteristic represents the cipher text as 1-D image. Consequently, the feasible values of the parameters $d$ and $\theta$ are narrowed to $d=1$ and $\theta=0$. Furthermore, the number of gray levels $G$ is mapped to 4 (given with the set $C$ ). Fig. 4 illustrates the text given in Cyrillic and Glagolitic scripts along with theirs cipher counterparts.

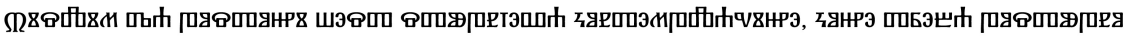

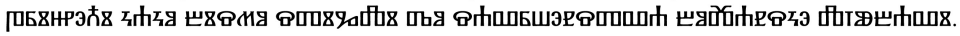

200100012000000000000200010000002110000000000001200002002000000010000000000210000100000000000110000100100

(a)

Мислим да постоји шест ступњева контемплације, које треба поступно пријећи како бисмо стигли до савршенства божанске љубави.

1000002000000300000002000000000000002030003002010000020000203010000010000000000200002000000010000000021000

Fig. 4. Text sample encryption: (a) Glagolitic script, and (b) Cyrillic script

The ciphers are subjected to co-occurrence analysis. Fig. 5 shows GLCM for each cipher (see Fig. 4 for reference). 


\begin{tabular}{|c|c|c|c|}
\hline 69 & 0 & 9 & 5 \\
\hline 0 & 0 & 0 & 0 \\
\hline 9 & 0 & 2 & 2 \\
\hline 6 & 0 & 2 & 0 \\
\hline
\end{tabular}

(a)

\begin{tabular}{|c|l|l|l|}
\hline 69 & 4 & 9 & 4 \\
\hline 6 & 0 & 0 & 0 \\
\hline 8 & 1 & 0 & 0 \\
\hline 4 & 0 & 0 & 0 \\
\hline
\end{tabular}

(b)

Fig. 5. GLCM obtained from the cipher (Fig. 4): (a) Glagolitic text encryption, and (b) Cyrillic text encryption

The probability version of the GLCM is given as:

$$
C(i, j)=\frac{P(i, j)}{\sum_{i, j}^{G} P(i, j)}
$$

\subsection{Features Extraction}

The number of texture features that can be extracted from the GLCM is 14 [6], [9]. Due to the similar origin of the Cyrillic and Glagolitic script [10] only four texture features is used. These four features are defined as:

$$
\begin{aligned}
\text { Dissimilarity } & =\sum_{i}^{G} \sum_{j}^{G} C(i, j) \cdot(i-j) \\
\text { Contrast } & =\sum_{i}^{G} \sum_{j}^{G} C(i, j) \cdot(i, j)^{2} \\
\text { Invdmoment } & =\sum_{i}^{G} \sum_{j}^{G} C(i, j) \cdot\left[1+(i-j)^{2}\right] \\
\text { Homogeneity } & =\sum_{i}^{G} \sum_{j}^{G} C(i, j) \cdot[1+(i-j)]
\end{aligned}
$$

\section{Experiment}

In the experiment, the custom oriented database that mainly consists of the documents given in 11] is adopted for the testing purposes. The database consists of 50 documents with the text length from 700 to 3000 characters. A few texts are written by George d'Esclavonie (i.e. Juraj Slovinac), who was the Croatian Glagolitic priest and professor at Sorbonne in Paris around 1400. They represent excerpts from his book Le Château de Virginité (i.e. The Castle of Virginity) written in 1411 [11-12. It is given in Fig. 6] 


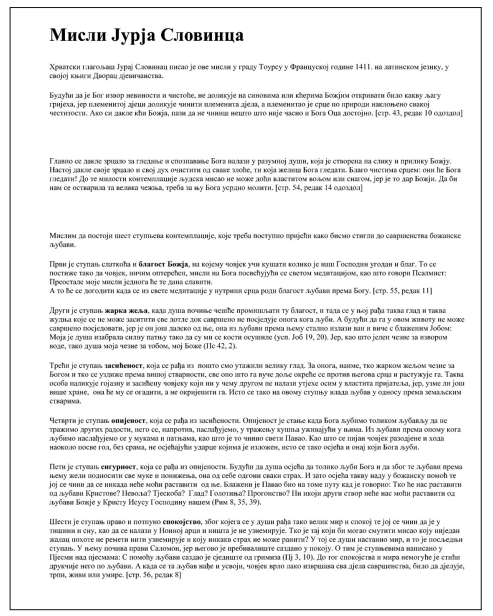

(a)

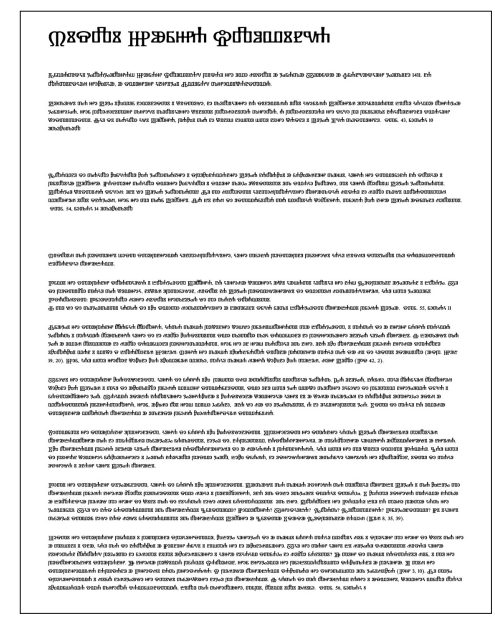

(b)

Fig. 6. Document samples excerpt from database: (a) Cyrillic document, and (b) Glagolitic document

\section{Results and Discussion}

According to the proposed algorithm, the documents from the database were encrypted to cipher and subjected to the co-occurrence analysis. The four GLCM texture features, i.e. dissimilarity, contrast, invdmoment and homogeneity were used to characterize the scripts. To evaluate the results, the minimum, maximum and mean values were used. Tables 102 show their values for Cyrillic and Glagolitic script, respectively.

These measures showed significant variation for both scripts. Hence, it is a starting point for their discrimination. Cyrillic script was characterized with

Table 1. Results of the experiment for Cyrillic text

\begin{tabular}{|c|c|c|c|c|}
\hline Cyrillic & Dissimilarity & Contrast & Invdmoment & Homogeneity \\
\hline Minimum & 0.5770 & 1.0649 & 0.7281 & 0.7641 \\
\hline Maximum & 0.6577 & 1.2275 & 0.7603 & 0.7920 \\
\hline Mean & 0.6150 & 1.1518 & 0.7462 & 0.7807 \\
\hline
\end{tabular}

Table 2. Results of the experiment for Glagolitic text

\begin{tabular}{ccccc}
\hline \hline Glagolitic & Dissimilarity & Contrast & Invdmoment Homogeneity \\
\hline \hline Minimum & 0.7375 & 1.6097 & 0.6723 & 0.7248 \\
Maximum & 0.8659 & 1.9180 & 0.7185 & 0.7638 \\
Mean & 0.8103 & 1.8197 & 0.6958 & 0.7449 \\
\hline \hline
\end{tabular}


Dissimilarity
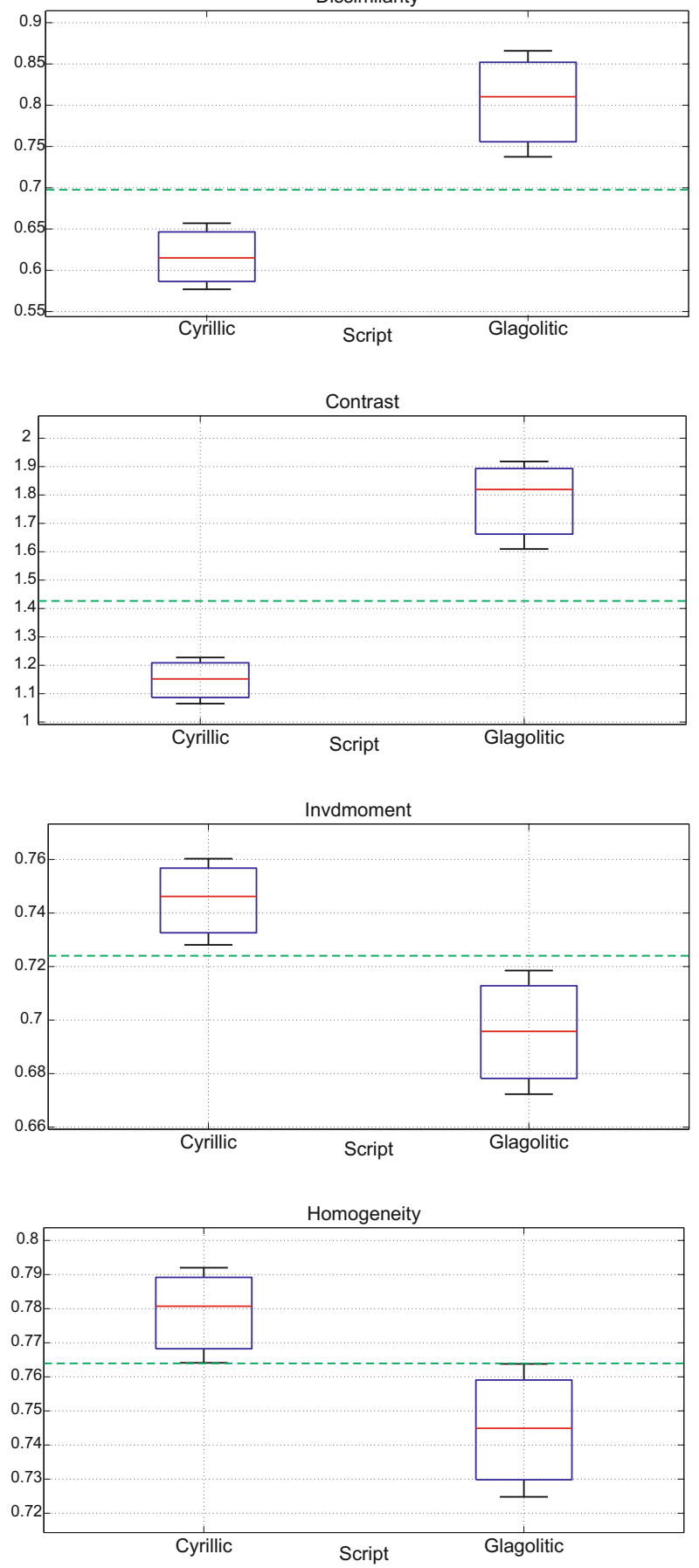

Fig. 7. GLCM features for Cyrillic and Glagolitic script: Dissimilarity (top), Contrast (middle top), Invdmoment (middle bottom), Homogeneity (bottom) 
dissimilarity below 0.66 , contrast below 1.23 , invdmoment above 0.72 and homogeneity above 0.764 . In contrast, Glagolitic script was distinguished with dissimilarity above 0.73 , contrast above 1.60, invdmoment below 0.72 and homogeneity below 0.764. Fig. 7 illustrates the comparison between scripts taking into account these texture features.

To quantify their differences, the ratio between given measures is established. Table 3 shows these ratio measures.

Table 3. Texture feature ratio measures

\begin{tabular}{|c|c|c|c|c|}
\hline Cyrillic/Glagolitic Ratio & Dissimilarity & Contrast & $\overline{\text { Invdmoment }}$ & Homogeneity \\
\hline Minimum & 0.6811 & 0.5602 & 1.0270 & 1.0122 \\
\hline Maximum & 0.8568 & 0.7273 & 1.1270 & 1.0911 \\
\hline Maximum & 0.7613 & 0.6355 & 1.0729 & 1.0483 \\
\hline Criteria & $<1$ & $<1$ & $>1$ & $>1$ \\
\hline
\end{tabular}

From the results given in Table 3 the discrimination criteria can be established. It is clear that dissimilarity and contrast received lower values for the text written in Cyrillic compared to the text written in Glagolitic script. On the contrary, indvmoment and homogeneity acquired higher values. Accordingly, these descriptors are suitable for establishing the discrimination between Cyrillic and Glagolitic script. The synergy of these four descriptors can define a strong margin in establishing criteria to distinguish a certain script. As the final result, we expect to create the solid criteria for recognition of the script in the Slavic documents. The criteria can be described with the following pseudo-code:

program Script_Distinction (Output)

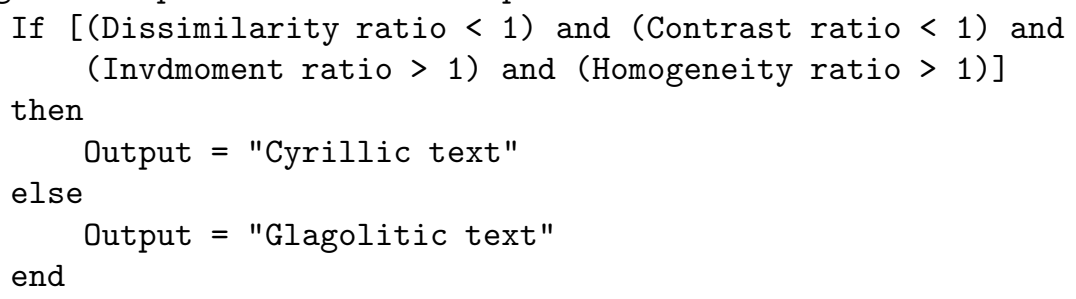

The proposed algorithm is characterized as computationally non-intensive. It is coded in Matlab without any programming parallelism. Testing indicated that typical processing time is as low as 0.1 seconds per text including around 2000 characters.

\section{Conclusion}

The paper proposed the algorithm for the script characterization and identification in the old Slavic printed documents that incorporate Cyrillic and Glagolitic 
scripts. The algorithm included the statistical analysis of the document based on the baseline status of each script element accompanied with the encryption. The statistical analysis was performed by co-occurrence analysis of the cipher. As a result, four texture features were extracted. Due to the difference in the script characteristics, the results of the statistical analysis showed significant diversity between both scripts. It represented the key point for decision-making process of script identification. The proposed method was tested on documents from the custom oriented database. The experiments gave encouraging results.

Future research will integrate the proposed algorithm into the preprocessing stage of the optical character recognition (OCR).

Acknowledgments. This work was partially supported by the Grant of the Ministry of Education, Science and Technological Development of the Republic Serbia, as a part of the project TR33037 and III43011 within the framework of Technological development program.

\section{References}

1. Ghosh, D., Dube, T., Shivaprasad, A.P.: Script Recognition - A Review. IEEE Transactions on Pattern Analysis and Machine Intelligence 32(12), 2142-2161 (2010)

2. Smith, C.: Basic Cryptanalysis Techniques. Tehnical Report, SANS Institute (2009)

3. Hoffstein, J., Pipher, J., Silverman, J.H.: An Introduction to Mathematical Cryptography. Springer, New York (2008)

4. Paar, C., Pelzl, J.: Hash Functions. In: Understanding Cryptography, A Text-book for Students and Practitioners, ch. 11. Springer, New York (2009)

5. Brodić, D., Milivojević, Z.N., Maluckov, Č.A.: Recognition of the Script in Serbian Documents using Frequency Occurrence and Co-occurrence Analysis. The Scientific World Journal 2013(896328), 1-14 (2013)

6. Haralick, R., Shanmugam, K., Dinstein, I.: Textural Features for Image Classification. IEEE Transactions on Systems, Man, and Cybernetics 3(6), 610-621 (1973)

7. Zramdini, A.W., Ingold, R.: Optical Font Recognition Using Typographical Features. IEEE Transaction on Pattern Analysis and Machine Intelligence 20(8), 877-882 (1998)

8. Zramdini, A.W., Ingold, R.: Optical Font Recognition from Projection Profiles. Electronic Publishing 6(3), 249-260 (1993)

9. Clausi, D.A.: An analysis of co-occurrence texture statistics as a function of grey level quantization. Canadian Journal of Remote Sensing 28(1), 45-62 (2002)

10. Iliev, I.G.: Short History of the Cyrillic Alphabet. International Journal of Russian Studies 2(2), 1-65 (2013)

11. http://www.croatianhistory.net/etf/juraj_slovinac_misli.html

12. Greenfield, J.: Notable Bindings II: MS 497: Le Château de Virginité. The Yale University Library Gazette 65(1/2), 43-45 (1990) 